\title{
The clinical features of papillary thyroid cancer in Hashimoto's thyroiditis patients from an area with a high prevalence of Hashimoto's disease
}

Ling Zhang ${ }^{\dagger}$, Hui Li ${ }^{\dagger}$, Qing-hai Ji, Yong-xue Zhu, Zhuo-ying Wang, Yu Wang, Cai-ping Huang, Qiang Shen, Duan-shu Li and Yi Wu

\begin{abstract}
Background: The goal of this study was to identify the clinicopathological factors of co-existing papillary thyroid cancer (PTC) in patients with Hashimoto's thyroiditis (HT) and provide information to aid in the diagnosis of such patients.

Methods: This study included 6109 patients treated in a university-based tertiary care cancer hospital over a 3-year period. All of the patients were categorised based on their final diagnosis. Several clinicopathological factors, such as age, gender, nodular size, invasive status, central compartment lymph node metastasis (CLNM) and serum thyroid-stimulating hormone (TSH) level, were compared between the various groups of patients.

Results: There were 653 patients with a final diagnosis of HT. More PTC was found in those with HT (58.3\%; 381 of 653) than those without HT (2416 of 5456; 44.3\%; p < 0.05). The HT patients with co-occurring PTC were more likely to be younger, be female, have smaller nodules and have higher TSH levels than those without PTC. A multivariate analysis indicated that the presence of HT and higher TSH levels were risk factors for a diagnosis of PTC. In the PTC patients, the presence of $\mathrm{HT}$ or another benign nodule was a protective factor for CLNM, whereas no significant association was found for TSH levels.

Conclusion: PTC and HT have a close relationship in this region of highly prevalent HT disease. Based on the results of our study, we hypothesise that long-term HT leads to elevated serum TSH, which is the real risk factor for thyroid cancer.
\end{abstract}

Keywords: Papillary thyroid carcinoma, Thyroid-stimulating hormone, Hashimoto's thyroiditis

\section{Background}

Thyroid cancer is the most common endocrine carcinoma, and papillary thyroid carcinoma (PTC) is the $7^{\text {th }}$ most common cancer among women in the world [1]. There are numerous risk factors for PTC, including radiation exposure, insufficient iodine intake, hormonal factors, and family history [2]. It is noteworthy that molecular analyses have indicated that lymphocytic infiltration is frequently observed in PTC, suggesting that immunological factors might be involved in tumour

\footnotetext{
* Correspondence: jiqinghai@shca.org.cn

${ }^{\dagger}$ Equal contributors

Department of Head \& Neck Surgery, Fudan University Cancer Hospital/

Center, Department of oncology, Fudan University Shanghai Medical College, 270 Dong An Road, Shanghai 200032, PR China
}

progression [3,4]. Hashimoto's thyroiditis $(\mathrm{HT})$ is the most common inflammatory thyroid disease and the most common cause of hypothyroidism in the United States, affecting 22 of every 100,000 individuals. In China, the rates are even higher, with approximately 0.4-1.5\% of the population affected, which accounts for $20-25 \%$ of the thyroid disease cases in this country [5-7].

Since Dailey et al. first proposed a relationship between HT and PTC in 1955 [8], there have been many reports on this topic, with conflicting conclusions. Certain authors have agreed that there may be a positive correlation between HT and PTC [8-14], whereas others have not [15-19].
() Biomed Central

(c) 2012 Zhang et al.; licensee BioMed Central Ltd. This is an Open Access article distributed under the terms of the Creative Commons Attribution License (http://creativecommons.org/licenses/by/2.0), which permits unrestricted use, distribution, and reproduction in any medium, provided the original work is properly cited. 
We performed a retrospective analysis of the relationship between HT and PTC using a large population sample from an area with a high HT prevalence.

\section{Results}

\section{Clinical characteristics}

In total, 6109 patients underwent thyroid surgery in our hospital during the study period (538 males and 4571 females); 3288 of these patients had a final diagnosis of benign thyroid nodule, and 2821 had a final diagnosis of PTC. The ages of the patients ranged from 8 to 88 years of age (mean, 46.1 \pm 12.3 years of age). There were 653 patients with HT in our study population. Age, female gender, and nodule size were significantly different between the patients with and without HT. The basic characteristics of the patients are shown in Table 1. Of the 6109 patients, 5115 patients had had their preoperative serum thyroid-stimulating hormone (TSH) and free thyroxine $\left(\mathrm{T}_{4}\right)$ concentrations measured within the 2 weeks before their surgery and were included in the TSH analysis. Due to the unavailability of their preoperative thyroid function, 994 patients were excluded from the TSH analysis. Among these patients, 260 were prescribed levothyroxine $\left(\mathrm{LT}_{4}\right)$ preoperatively, and the remainder did not have a serum thyroid function test within the 2 weeks prior to their surgery. The 994 patients included 25 patients with HT (23 cases with co-occurring PTC and 2 with benign disease) and 969 patients without HT (178 patients with PTC and 791 with benign disease). All the 5115 patients fulfilled the following criteria: 1) They were not taking L-T4 or methimazole and were not overtly hyperthyroid or hypothyroid. 2) They had $\mathrm{TSH}$, free thyroid hormones and thyroidglobulin antibodies measured within one week prior to thyroidectomy. 3) They had not undergone any type of previous thyroid surgery.

We then analysed the serum TSH levels of the 5115 patients in the TSH analysis to determine the association between PTC and HT.

Table 1 General status

\begin{tabular}{lccc}
\hline & $\begin{array}{c}\text { With } \\
\text { Hashimoto's }\end{array}$ & $\begin{array}{c}\text { Without } \\
\text { Hashimoto's }\end{array}$ & $\begin{array}{c}\mathbf{P} \\
\text { value }\end{array}$ \\
\hline Number of patients & 653 & 5456 & \\
$\begin{array}{l}\text { Age (years) } \\
\text { Gender }\end{array}$ & $44.4 \pm 11.9$ & $46.3 \pm 12.3$ & 0.077 \\
Male & 56 & 1482 & 0.001 \\
Female & 597 & 3974 & \\
Nodule Size (cm) & $1.75 \pm 1.23$ & $2.26 \pm 1.48$ & 0.001 \\
PTC & $381(58.3 \%)$ & $2440(44.3 \%)$ & 0.001 \\
PTC cancer with serum & $358(54.8 \%)$ & $2262(41.6 \%)$ & 0.001 \\
TSH & & & \\
\hline
\end{tabular}

\section{Comparison of the clinicopathological factors between patients with and without HT}

In the first phase of the study, we compared the clinicopathological factors of the patients with and without HT. A total of 628 patients with HT and 4487 patients without HT had a serum TSH examination before their surgery. In comparing the patients with and without HT, it was found that gender (female), age, nodule size and serum TSH levels were significant indicators of a positive HT diagnosis. Subsequently, the following factors were compared between the 2 sub-groups: 1) if the patients with HT suffered from PTC; and 2) if the patients with benign disease suffered from HT. The results show that in the patients with HT, both with and without PTC, the patient's age, nodule size and serum TSH level still were significant indicators of a positive HT diagnosis (made a difference), whereas the gender (female) was not. In the patients with benign disease, both with and without HT, the patient's gender (female), age, nodule size and serum $\mathrm{TSH}$ level also were significant indicators of a positive diagnosis (Table 2).

\section{Comparison of the clinicopathological factors among patients with PTC}

In the second phase of the study, we examined the clinicopathological factors, including HT, in the patients with PTC. Among the patients with PTC, both with and without HT, it was found that gender (female), nodule size, central compartment lymph node metastasis (CLNM) and serum TSH level had a significant difference. Furthermore, we compared the patients with both PTC and HT with the patients with PTC only and the patients with PTC and co-occurring benign diseases. The results show that age, gender (female), CLNM and serum TSH level all differed in the two comparisons. The nodule size only differed in the comparison between the patients suffering from PTC with HT and patients suffering from PTC with benign diseases. The invasion of a primary tumour only differed in the comparison between the patients with PTC and co-occurring HT and patients with PTC only (Table 3).

\section{Independent risk factors for PTC}

After the two phases discussed above, the clinicopathological factors were examined in univariate and multivariate analyses to assess the PTC risk factors in all 5115 patients. In the univariate analysis, it was found that age ( $>45$ years of age) and nodule size $(>1 \mathrm{~cm})$ had significant odds ratios (ORs) less than 1, whereas HT and serum TSH had significant ORs greater than 1 . In the multivariate analysis, these four factors were also significant. Interestingly, the HT had an OR of less than 1 after the multivariate analysis (Table 4). 
Table 2 Comparison of the clinicopathological factors in patients with or without HT

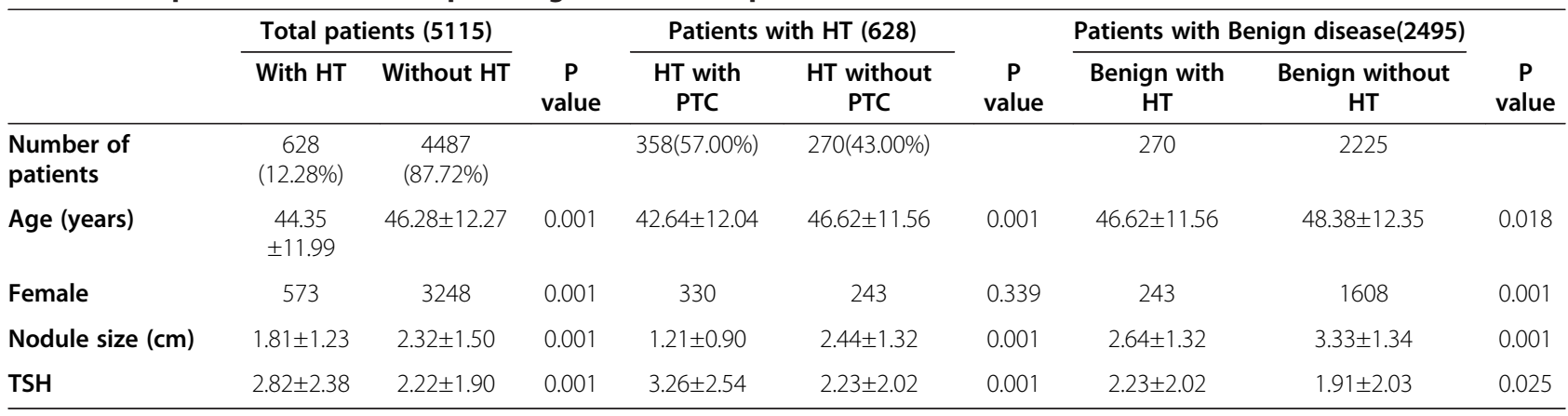

*:All the patients in the table had serum TSH test.

\section{Independent risk factors for level VI lymph node metastasis}

Because prophylactic central lymph node dissection (CLND) was routinely performed for PTC patients at our hospital, univariate and multivariate analyses of the CLNM were also performed. The results of the univariate analysis showed that PTC patients with HT and PTC patients with benign disease had a significant OR of less than 1 , whereas nodule size $(>1 \mathrm{~cm})$, serum TSH level and invasion by the primary tumour had significant ORs greater than 1 . In the multivariate analysis, the PTC patients with HT and PTC patients with benign disease also showed a protective effect, whereas only nodule size $(>1 \mathrm{~cm})$ and invasion by the primary tumour were associated with increased risk (Table 5).

\section{Histomorphological features of HT and PTC}

Based on all of the pathological results of the patients in our study population, four typical figures were chosen to show the histomorphological features of HT only, PTC only and HT co-existence with PTC. Additional file 1: Figure S1 shows the histomorphological features of HT, which consisted of the typical germinal centres of HT. Additional file 1: Figure S2 and Figure S3 show the histomorphological features of HT co-existence with PTC. These two figures show the close histomorphological relationship between HT and PTC. Additional file 1: Figure S4 shows the typical histomorphological features of PTC.

\section{Discussion}

Both HT and PTC have a high prevalence worldwide, and these conditions may have a close relationship. Thus, there may be many patients who have both diseases simultaneously. Whether PTC represents a reactive response to $\mathrm{HT}$ or $\mathrm{HT}$ is a prerequisite tumourigenic event still remains to be determined.

In our population, 653 patients suffered from HT during the period from 2008 to 2010. Of these patients, $58.3 \%$ had co-occurring PTC, which was a higher rate than in previous reports [8-19]. If the patients were subdivided by gender, the result was statistically significant for the females with HT. Compared with the females without HT, the women with HT were found to be approximately $30 \%$ more likely to have co-occurring PTC. Our findings in this patient population support the previous studies linking HT with PTC $[10,13,20]$.

At the molecular level, the evidence shows that HT may be a precursor of PTC. It is well known that RET was the first activated receptor-tyrosine kinase to be identified in papillary thyroid cancer. The proto-oncogene, located on chromosome 10q11.2, encodes a transmembrane

Table 3 Comparison of the clinicopathological factors in PTC patients with TSH

\begin{tabular}{|c|c|c|c|c|c|c|c|c|c|}
\hline & PTC with HT & PTC without HT & $P$ value & PTC with HT & PTC only & $P$ value & PTC with HT & PTC with Benign & $P$ value \\
\hline Number of patients & $358(13.67 \%)$ & 2262(86.34\%) & & $358(13.67 \%)$ & $1270(48.47 \%)$ & & $358(13.67 \%)$ & $992(37.86 \%)$ & \\
\hline Age (years) & $42.64 \pm 12.04$ & $44.21 \pm 11.83$ & 0.058 & $42.64 \pm 12.04$ & $44.29 \pm 11.73$ & 0.020 & $42.64 \pm 12.04$ & $44.12 \pm 11.95$ & 0.023 \\
\hline Female & 350 & 1640 & 0.001 & 350 & 925 & 0.000 & 350 & 715 & 0.001 \\
\hline Nodule size $(\mathrm{cm})$ & $1.21 \pm 0.90$ & $1.33 \pm 0.81$ & 0.001 & $1.21 \pm 0.90$ & $1.23 \pm 0.78$ & 0.845 & $1.21 \pm 0.90$ & $1.45 \pm 0.84$ & 0.001 \\
\hline Invasion & 69 & 506 & 0.250 & 69 & 342 & 0.003 & 69 & 164 & 0.178 \\
\hline Level VI & 153 & 1358 & 0.001 & 153 & 827 & 0.001 & 153 & 531 & 0.001 \\
\hline Lateral $^{\&}$ & 37 & 349 & 0.133 & 37 & 216 & 0.635 & 37 & 133 & 0.427 \\
\hline TSH & $3.26 \pm 2.54$ & $2.53 \pm 1.72$ & 0.001 & $3.26 \pm 2.54$ & $2.45 \pm 1.59$ & 0.001 & $3.26 \pm 2.54$ & $2.63 \pm 1.86$ & 0.001 \\
\hline
\end{tabular}

* total number of PTC patients with TSH : 2620.

$\&_{\text {:Lateral neck metastasis }}{ }^{*}$. 
Table 4 Independent risk factors for papillary thyroid cancer, as identified by the univariate and multivariate logistic regression analyses

\begin{tabular}{|c|c|c|c|c|}
\hline & Unadjusted OR $(95 \% \mathrm{Cl})$ & $P$ value & Adjusted OR $(95 \% \mathrm{Cl})$ & $P$ value \\
\hline Gender (Male vs. Female) & 1.054 (0.930-1.196) & 0.410 & $0.927(0.796-1.080)$ & 0.329 \\
\hline Age ( $\leq 45$ years vs. $>45$ years) & $0.520(0.465-0.581)$ & 0.001 & $0.505(0.442-0.576)$ & 0.001 \\
\hline HT (HT vs. no HT) & $1.304(1.102-1.544)$ & 0.002 & $0.859(0.724-0.998)$ & 0.001 \\
\hline Nodule size (>1 cm vs. $\leq 1 \mathrm{~cm})$ & $0.010(0.006-0.016)$ & 0.001 & $0.009(0.005-0.014)$ & 0.001 \\
\hline TSH (constant) & $1.303(1.254-1.355)$ & 0.001 & $1.361(1.304-1.421)$ & 0.001 \\
\hline
\end{tabular}

receptor-tyrosine kinase with four cadherin-related motifs in the extracellular domain [21]. The reported overall prevalence of RET/PTC rearrangements in papillary carcinomas varies from $3 \%$ to as high as $85 \%$, depending on the detection methods and geographical location of the patients; a reasonable range is $13-43 \%$ [22-27]. Moreover, $\mathrm{RET} / \mathrm{PTC}$ rearrangements have also been reported in the thyroids of patients with the autoimmune inflammatory condition known as Hashimoto's thyroiditis [28-31]. However, these findings are controversial and might reflect either PCR contamination or the presence of microscopic nodules of papillary carcinoma, as studies that have excluded these possibilities do not confirm the data [32,33]. Whether RET/PTC rearrangements induce HT to PTC remains unknown. The connection of RET/PTC rearrangements in HT and PTC requires further investigation.

However, several retrospective and prospective studies have found no correlation between these two diseases. Interestingly, our univariate analysis found that HT is a risk factor for PTC, whereas HT played a protective role in the multivariate analysis, which is consistent with previous reports. It is difficult to explain this phenomenon. It has been hypothesised that serum TSH levels may play an important role. Since Boalart et al. found that elevated serum TSH can be a risk factor for PTC [34], many studies have replicated their results [15,35-41]. Thus, when considering whether HT is a risk factor for PTC, it is important to evaluate the serum TSH level. In our study, most of the patients' serum TSH levels were evaluated before their surgeries. As Table 2 and Table 3 show, the HT patients had higher TSH levels than the patients without HT. Moreover, the patients with cooccurring $\mathrm{HT}$ and PTC had the highest serum $\mathrm{TSH}$ levels among all of the sub-groups.

It is well known that serum TSH has a trophic effect on follicular-cell-derived thyroid cancer growth. Unfortunately, the present study could not provide evidence concerning the malignant transformation of thyroid follicular cells in the TSH-cAMP pathway. Recently, genome-wide association studies (GWAS) and carefully designed candidate gene approaches have determined that the FOXE1 genetic variant, which is downstream of the TSH-cAMP pathway, is the suspected risk factor for follicular-cell-derived thyroid cancer [42-44]. In the future, genetic studies may provide stronger evidence supporting the theory that high TSH levels cause thyroid cancer. When considering HT, it should be recognised that long-term HT can cause hypothyroidism, which elevates the serum TSH level. In China, where iodine intake is increasing, there is a high prevalence of HT and hypothyroidism in subjects with euthyroidism [7]. In our study, the rates of co-occurring PTC in the HT patients were higher than those in previous reports [8-19]. Considering these results, we hypothesise that long-term HT causes elevated serum TSH, which is the real thyroid cancer risk factor. This hypothesis may explain why HT was a risk factor in the univariate analysis, whereas in the multivariate analysis, which controlled for TSH levels, HT became a protective factor. Furthermore, this hypothesis may explain why several of the prospective studies that have examined the association between HT and thyroid cancer have found negative results (i.e., because the HT patients in these studies did not have high

Table 5 Independent risk factors for central lymph node metastatic papillary thyroid cancer, as identified by univariate and multivariate logistic regression analyses

\begin{tabular}{|c|c|c|c|c|}
\hline & Unadjusted OR (95\% Cl) & $P$ value & Adjusted OR (95\% Cl) & $P$ value \\
\hline Gender (Male vs. Female) & $0.865(0.722-1.037)$ & 0.117 & $0.932(0.763-1.139)$ & 0.493 \\
\hline Age ( $\leq 45$ years vs. $>45$ years) & $1.079(0.923-1.261)$ & 0.341 & $1.110(0.933-1.319)$ & 0.239 \\
\hline HT (HT vs. no HT) & $0.497(0.396-0.623)$ & 0.001 & $0.450(0.347-0.583)$ & 0.001 \\
\hline Nodule Size (>1 cm vs. $\leq 1 \mathrm{~cm}$ ) & $2.507(2.138-2.941)$ & 0.001 & $2.332(1.944-2.797)$ & 0.001 \\
\hline TSH (constant) & $1.303(1.254-1.355)$ & 0.001 & $1.008(0.962-1.057)$ & 0.727 \\
\hline With benign (with vs. without) & $0.814(0.696-0.952)$ & 0.001 & $0.670(0.559-0.802)$ & 0.001 \\
\hline Invasion (yes vs. no) & $9.804(7.346-13.084)$ & 0.001 & $10.092(7.382-13.797)$ & 0.001 \\
\hline
\end{tabular}


serum TSH levels for a long period). Since TSH is a growth factor for PTC, the serum TSH could be an individual marker for each HT patient. In clinic, doctors could control the serum TSH level under a lower level in the normal range of TSH for HT patients [45].

With regard to the clinical course, thyroid tumours associated with HT do not appear to be any more aggressive than those not associated with HT $[20,46]$. In our series of studies, we found that PTC patients with HT had less aggressive tumours than the patients with PTC only. Interestingly, the PTC patients with HT had less CLNM than those without HT (Table 3). This result conflicts with those of a previous report [14]. In Table 5, TSH is not a factor associated with an increased risk of central lymph node metastases in patients with PTC, which is not in agreement with Kim's study [47]. The Kim's study included only 554 patients, which was less than our patients. This might cause our different result. Furthermore, we take TSH as a constants variable, while Kim's study considered TSH as a dichotomous variable.

Recently, Hanahan et al. proposed a new hallmark of cancer genesis: "Tumor-Promoting Inflammation." [48] This new hallmark could play an important role in the pathogenic process of co-occurring PTC and HT. In certain cases, it is evident that inflammation is present at the earliest stages of neoplastic progression and capable of fostering the development of incipient neoplasia into cancer and causing the invasion and metastasis of existing cancer $[49,50]$. It is certain that in the near future, the relationship between inflammation and cancer invasion or metastasis will be further elucidated.

Consistent with previous reports [14,15], our study also found that a nodule $>1 \mathrm{~cm}$ plays a protective role in our study population (Table 4). This finding may have been due to the selection of patients for surgery. Patients with the small benign nodules are typically not sent to surgery, whereas patients with larger benign nodules, especially $>4 \mathrm{~cm}$, are more likely to be candidates for surgical treatment. However, in PTC patients, a primary tumour $>1 \mathrm{~cm}$ is a risk factor for neck metastasis (Table 5). Also, there was an interesting phenomenon that the cancer size of "PTC with benign disease" is larger than "PTC only" or "PTC with HT", while "PTC with benign diseas" shows less or similar invasion. This might be due to the different genetic origin of different types of PTC. The genesis of "PTC with benign nodule" might come from the benign nodule, which is less invasion [51]. The genesis of "PTC only" might come from the somatic mutation, which is more invasion.

In the morphological examination, an extensive relationship was shown between HT and PTC (Additional file 1: Figure S1-S4). Thus, based on the histomorphological features, laboratory findings and clinical data, the co-occurrence of PTC and HT is an interesting topic concerning thyroid cancer research and cancer hallmarks.

We also have some limitations in this study. Since our study is a retrospective cross-section study, there could be a selection bias in the incidence of PTC in HT. The number of HT patients who develop nodules was not given. Next, we could not estimate the mean time for the HT patient who would suffer from PTC. It is necessary that the basic research on raised TSH causing PTC in HT patients should be done in the future, which could provide more powerful evidence for the correlation of HT and PTC.

\section{Conclusion}

PTC and HT have a close relationship in an area with a high prevalence of HT disease. Based on the results of our study, we hypothesise that long-term HT could cause elevated serum TSH, which is the real risk factor for the development of thyroid cancer. Furthermore, the disease's invasiveness and metastasis in patients suffering from both PTC and HT could be used as a model in studies investigating inflammation and cancer progression. Additional research should focus on this interesting issue.

\section{Methods}

\section{Patients}

The study subjects were all patients treated from January, 2008, to December, 2010, at the Department of Head and Neck Surgery at the Cancer Hospital of Fudan University in Shanghai, China. All of the patients provided written informed consent for their information to be stored in the hospital database and used for research, and the study was approved by the Ethical Committee of the Cancer Hospital of Fudan University. The patients included in the study met the following criteria: no previous thyroid surgery, no PTC or benign thyroid nodule confirmed by histopathology, and the availability of an adequate medical history. A total of 6109 patients were included in this study.

All patients with thyroid nodules underwent a thyroid US examination in our hospital. In our hospital, we selected patients with thyroid nodules for surgery based on the suspicious features on the ultrasound images, which were defined as micro-calcification, hypo-echoic, increased nodular vascularity, infiltrative margin and taller than wide on transverse view. A suspicious malignant nodule was diagnosed when at least one of the above images was present. Surgical operation was suggested in patients with at least one suspicious malignant nodule.

If more than one nodule were found under US, each nodule in the whole thyroid gland was evaluated by one clinical physician at the same time. 
All patients that have not undergone operation were followed with serial US examinations every 3-6 months, especially in those with suspicious malignant nodule but rejected the surgery suggestion considering the relative good prognosis of PTMC and the potential risk of the operation. Surgery was indicated during period of follow-up when there was more than a $50 \%$ change in volume of suspicious malignant nodules or presence of at least one suspicious US feature mentioned above in other nodules.

In abstract, there were three criteria for our selecting patients before surgery.

1. suspect ultrasound images, for example, microcalcifications, hypoechoic, increased nodular vascularity, infiltrative margins and taller than wide on transverse view.

2. ultrasound images changed in the 3-6 months follow-up

3. patients consent.

This was described in our previous paper [52]. For patients with benign nodules, surgery only was done in the nodule larger than $4 \mathrm{~cm}$.

\section{Histopathology}

Resected surgical specimens were fixed in 10\% formalin and cut at 5-um intervals. One to 3 representative sections of the tumour and all suspicious lesions were submitted for microscopy. All of the sections were fixed in formalin, embedded in paraffin wax, and stained with haematoxylin and eosin. HT was diagnosed by the presence of diffuse lymphoplasmacytic infiltrations with germinal centres, parenchymal atrophy with oncocytic changes, and variable amounts of stromal fibrosis throughout the thyroid gland. We examined and recorded any coexisting HT in all of the patients included in the study.

\section{Serum thyroid function measurement}

In our hospital, serum fT4, fT3, and TSH are measured by a chemiluminescent microparticle immunoassay (Abbott Laboratories, Abbott Park, IL 60064, USA) that has interassay coefficients of variations of less than $10 \%$ over the ranges $2.63-5.70 \mathrm{pmol} / \mathrm{litre}, 9.01-19.05 \mathrm{pmol} /$ litre, and $0.35-4.94 \mu \mathrm{IU} / \mathrm{mlitre}$.

\section{Clinicopathologic variables assessed}

The following variables were used in our study: gender, age at diagnosis, maximal microscopic tumour size (the largest diameter; for multifocal lesions, the maximal microscopic tumour size of the largest lesion was used, as outlined by the AJCC $7^{\text {th }}$ edition), primary tumour invasion and central lymph node status. Prophylactic CLND was routinely performed when the results of the frozen section indicated a malignant nodule. Invasion of the primary tumour consisted of gross extrathyroidal extension and microscopic extrathyroidal extension, which were assessed in the final pathology. The final pathology decided the status of the lateral neck lymph nodes and if there was central lymph node metastasis.

\section{Statistical analysis}

The results are expressed as the means \pm standard deviation (SD). The statistical analysis was performed using a Student's T test or Mann-Whitney test or chi-square test, when appropriate. ORs with 95\% confidence intervals (CIs) for the relationships between the variables and PTC were calculated using binary logistic regression. A p-value of less than 0.05 was considered statistically significant. The statistical analyses were performed using SPSS software, version 12.0 (SPSS, Chicago, IL, USA).

\section{Additional file}

Additional file 1: Figure S1. Hashimoto's thyroiditis. Germinal centers have formed in the gland and are associated with the smaller follicles and the oxyphilic follicular cells. HE x 200. Figure S2. Papillary carcinoma arises in the background OF Hashimoto's thyroiditis. HE x 40. Figure S3. PTC co-existence with HT. The carcinoma area (the lower portion) is next to Hashimoto's thyroiditis area(the upper portion). HE x 200. Figure S4. PTC Distinct papillary structures are seen. A giant cell, common in papillary carcinoma, is seen in this section. HE x 200.

\section{Abbreviations \\ PTC: Papillary thyroid cancer; HT: Hashimoto's thyroiditis; CLNM: Central compartment lymph node metastasis; TSH: Serum thyroid stimulating hormone; fT3: free triiodothyronine; fT4: free thyroxine; LT4: Levothyroxine; OR: Odds rate; CLND: Central lymph node dissection; GWAS: Genome-wide association studies; SD: Standard deviation; Cl: Confidence intervals.}

\section{Competing interests}

The authors have declared that no competing interests exist.

\section{Authors' contributions}

LZ and HL had equally made substantial contributions to acquisition of data, analysis and interpretation of data and draft the manuscript for important intellectual content. QJ made contribution to the conception and design of this study; give final approval of the version to be published. YZ, ZW, YW, CH and QS made contributions to acquisition of data. DL and YW made contributions to interpretation of data. All authors read and approved the final manuscript.

\section{Acknowledgement}

This research is supported by grants from the National Natural Science Foundation of China (30872958). The funders had no role in study design, data collection and analysis, decision to publish, or preparation of the manuscript.

Received: 9 January 2012 Accepted: 25 November 2012 Published: 21 December 2012

\section{References}

1. Jemal A, Bray F, Center MM, Ferlay J, Ward E, Forman D: Global cancer statistics. CA Cancer J Clin 2011, 61:69-90.

2. Kondo T, Ezzat S, Asa SL: Pathogenetic mechanisms in thyroid follicularcell neoplasia. Nat Rev Cancer 2006, 6:292-306.

3. Gasbarri A, Sciacchitano S, Marasco A, Papotti M, Di Napoli A, Marzullo A, Yushkov P, Ruco L, Bartolazzi A: Detection and molecular characterisation 
of thyroid cancer precursor lesions in a specific subset of Hashimoto's thyroiditis. Br J Cancer 2004, 91:1096-1104.

4. Prasad ML, Huang Y, Pellegata NS, de la Chapelle A, Kloos RT: Hashimoto's thyroiditis with papillary thyroid carcinoma (PTC)-like nuclear alterations express molecular markers of PTC. Histopathology 2004, 45:39-46.

5. Lal G, Clark OH: Textbook of endocrine surgery. Philadelphia: Saunders; Chronic Thyroiditis; 2005:38-40.

6. Kumar V, Robbins SL: Robbins basic pathology, The endocrine system. Philadelphia, PA: Saunders/Elsevier; 2007

7. Teng W, Shan Z, Teng X, Guan H, Li Y, Teng D, Jin Y, Yu X, Fan C, Chong W, Yang F, Dai H, Yu Y, Li J, Chen Y, Zhao D, Shi X, Hu F, Mao J, Gu X, Yang R, Tong Y, Wang W, Gao T, Li C: Effect of iodine intake on thyroid diseases in China. Nengl J Med 2006, 354:2783-2793.

8. Dailey ME, Lindsay S, Skahen R: Relation of thyroid neoplasms to Hashimoto disease of the thyroid gland. AMA Arch Surg 1955, 70:291-297.

9. Hirabayashi RN, Lindsay S: The relation of thyroid carcinoma and chronic thyroiditis. Surg Gynecol Obstet 1965, 121:243-252.

10. Singh B, Shaha AR, Trivedi H, Carew JF, Poluri A, Shah JP: Coexistent Hashimoto's thyroiditis with papillary thyroid carcinoma: impact on presentation, management, and outcome. Surgery 1999, 126:1070-1076.

11. Ott RA, McCall AR, McHenry C, Jarosz H, Armin A, Lawrence AM, Paloyan E: The incidence of thyroid carcinoma in Hashimoto's thyroiditis. Am Surg 1987, 53:442-445.

12. Okayasu I, Fujiwara M, Hara Y, Tanaka Y, Rose NR: Association of chronic lymphocytic thyroiditis and thyroid papillary carcinoma. A study of surgical cases among Japanese, and white and African Americans. Cancer 1995, 76:2312-2318.

13. Repplinger D, Bargren A, Zhang YW, Adler JT, Haymart M, Chen H: Is Hashimoto's thyroiditis a risk factor for papillary thyroid cancer? I Surg Res 2008, 150:49-52.

14. Kim KW, Park YJ, Kim EH, Park SY, Park do J, Ahn SH, Park do J, Jang HC, Cho BY: Elevated risk of papillary thyroid cancer in Korean patients with Hashimoto's thyroiditis. Head Neck 2011, 33:691-695.

15. Haymart MR, Repplinger DJ, Leverson GE, Elson DF, Sippel RS, Jaume JC, Chen $\mathrm{H}$ : Higher serum thyroid stimulating hormone level in thyroid nodule patients is associated with greater risks of differentiated thyroid cancer and advanced tumor stage. J Clin Endocrinol Metab 2008, 93:809-814.

16. Holm LE, Blomgren H, Lowhagen T: Cancer risks in patients with chronic lymphocytic thyroiditis. N Engl J Med 1985, 312:601-604.

17. Rago T, Di Coscio G, Ugolini C, Scutari M, Basolo F, Latofa F, Romani R, Berti P, Grasso L, Braverman LE, Pinchera A, Vitti P: Clinical features of thyroid autoimmunity are associated with thyroiditis on histology and are not predictive of malignancy in 570 patients with indeterminate nodules on cytology who had a thyroidectomy. Clin Endocrinol (Oxf) 2007, 67:363-369.

18. Crile G Jr: Struma lymphomatosa and carcinoma of the thyroid. Surg Gynecol Obstet 1978, 147:350-352.

19. Anil C, Goksel S, Gursoy A: Hashimoto's thyroiditis is not associated with increased risk of thyroid cancer in patients with thyroid nodules: a single-center prospective study. Thyroid 2010, 20:601-606.

20. Cipolla C, Sandonato L, Graceffa G, Fricano S, Torcivia A, Vieni S, Latteri S, Latteri MA: Hashimoto thyroiditis coexistent with papillary thyroid carcinoma. Am Surg 2005, 71:874-878.

21. Takahashi M, Buma $Y$, Iwamoto $T$, Inaguma $Y$, Ikeda H, Hiai H: Cloning and expression of the ret proto-oncogene encoding a tyrosine kinase with two potential transmembrane domains. Oncogene 1988, 3:571-578.

22. Tallini G, Asa SL: RET oncogene activation in papillary thyroid carcinoma. Adv Anat Pathol 2001, 8:345-354.

23. Tallini G, Santoro M, Helie M, Carlomagno F, Salvatore G, Chiappetta G Carcanqiu ML, Fusco A: RET/PTC oncogene activation defines a subset of papillary thyroid carcinomas lacking evidence of progression to poorly differentiated or undifferentiated tumor phenotypes. Clin Cancer Res 1998, 4:287-294

24. Lam AK, Montone KT, Nolan KA, Livolsi VA: Ret oncogene activation in papillary thyroid carcinoma: prevalence and implication on the histological parameters. Hum Pathol 1998, 29:565-568.

25. Sugg SL, Ezzat S, Zheng L, Freeman JL, Rosen IB, Asa SL: Oncogene profile of papillary thyroid carcinoma. Surgery 1999, 125:46-52.

26. Musholt TJ, Musholt PB, Khaladj N, Schulz D, Scheumann GF, Klempnauer J: Prognostic significance of RET and NTRK1 rearrangements in sporadic papillary thyroid carcinoma. Surgery 2000, 128:984-993.
27. Nakazawa T, Kondo T, Kobayashi Y, Takamura N, Murata S, Kameyama K, Muramastsu A, Ito K, Kobayashi M, Katoh R: RET gene rearrangements (RET/ PTC1 and RET/PTC3) in papillary thyroid carcinomas from an iodine-rich country (Japan). Cancer 2005, 104:943-951.

28. Sheils OM, O'Eary JJ, Uhlmann V, Lattich K, Sweeney EC: Ret/PTC-1 activation in Hashimoto Thyroiditis. Int J Surg Pathol 2000, 8:185-189.

29. Wirtschafter A, Schmidt R, Rosen D, Kundu N, Santoro M, Fusco A, Multhaupt H, Atkins JP, Rosen MR, Keane WM, Rothstein JL: Expression of the RET/PTC fusion gene as a marker for papillary carcinoma in Hashimoto's thyroiditis. Laryngoscope 1997, 107:95-100.

30. Arif S, Blanes A, Diza-Cano SJ: Hshimoto's thyroiditis share features with early papillary thyoid carcinoma. Histopathology 2002, 41:357-362.

31. Unger P, Ewart M, Wang BY, Gan L, Kohtz DS, Burstein DE: Expression of p63 in papillary thyroid carcinoma and in Hashimoto's thyroiditis: a pathobiologic link? Hum Pathol 2003, 34:764-769.

32. Nikiforova MN, Caudill CM, Biddinger P, Nikiforova YE: Prevalence of RET/ PTC rearrangements in Hashimoto's thyroiditis and papillary thyroid carcinomas. Int J Surg Pathol 2002, 10:15-22.

33. Sugg SL, Ezzat S, Rosen IB, Freeman JL, Asa SL: Distinct multiple RET/PTC gene rearrangements in multifocal papillary thyroid neoplasia. J Clin Endocrinol Metab 1998, 83:4116-4122.

34. Boelaert K, Horacek J, Holder RL, Wtkinson JC, Sheppard MC, Franklyn JA: Serum thyrotropin concentration as a novel predictor of malignancy in thyroid nodules investigated by fine-needle aspiration. J Clin Endocrinol Metab 2006, 91:4295-4301.

35. Hovens GC, Stokkel MP, Kievit J, Corssmit EP, Pereira AM, Romijn JA, Smit JW: Associations of serum thyrotropin concentrations with recurrence and death in differentiated thyroid cancer. J Clin Endocrinol Metab 2007, 92:2610-2615.

36. Polyzos SA, Kita M, Efstathiadou Z, Slavakis A, Sofianou D, Flaris N, Leontsini M, Kourtis A, Avramidis A: Serum thyrotropin concentration as a biochemical predictor of thyroid malignancy in patients presenting with thyroid nodules. J Can Res Clin Onco 2008, 134:953-960.

37. Jonklaas J, Nsouli-Maktabi H, Soldin SJ: Endogenous thyrotropin and triiodothyronine concentrations in individuals with thyroid cancer. Thyroid 2008, 18:943-952.

38. Haymart MR, Glinberg SL, Liu J, Sippel RS, Jaume JC, Chen H: Higher serum TSH in thyroid cancer patients occurs independent of age and correlates with extrathyroidal extension. Clin Endocrinology(Oxf) 2009, 73:434-439.

39. Fiore E, Rago T, Provenzale MA, Scitari M, Uqolini C, Basolo F, Di coscio G, Berti P, Grasso L, Elisei R, Pinchera A, Vitti P: Lower levels of TSH are associated to a lower risk of papillary thyroid cancer in patients with thyroid nodular disease: thyroid autonomy may play a protective role. Endocr Relat Cancer 2009, 16:1251-1260.

40. Jin J, Machekano R, McHenry CR: The utility of preoperative serum thyroid-stimulating hormone level for predicting malignant nodular thyroid disease. Am J Surg 2010, 199:294-298.

41. Kim ES, Lim DJ, Baek KH, Lee JM, Kim MK, Kwon HS, Song KH, Kang MI, Cha BY, Lee KW, Son HY: Thyroglobulin antibody is associated with increased cancer risk in thyroid nodules. Thyroid 2010, 20:885-891.

42. Gudmundsson J, Sulem P, Gudbjartsson DF, Jonasoon JG, Sigurdsson A, Bergthorsson JT, He H, Blondal T, Geller F, Jakobsdottir M, Magnusdottir DN, Matthiasdottir S, Stacey SN, Skarphedinsson OB, Helgadottir H, Li W, Nagy R, Aquillo E, Faure E, Prats E, Saez B, Martinez M, Eyjolfsson Gl, Bjornsdottir US, Holm H, Kristjansson K, Frigge ML, Kristvinsson H, Gulcher JR, Jonsson T, et al: Common variants on $9 \mathrm{q} 22.33$ and $14 \mathrm{q} 13.3$ predispose to thyroid cancer in European populations. Nat Genet 2009, 4:460-464.

43. Landa I, Ruiz-Llorente S, Montero-Conde C, Inglada-Pérez L, Schiavi F, Leskelä S, Pita G, Milne R, Maravall J, Ramos I, Andía V, Rodríguez-Poyo P, Jara-Albarrán A, Meoro A, del Peso C, Arribas L, Iglesias P, Caballero J, Serrano J, Picó A, Pomares F, Giménez G, López-Mondéjar P, Castello R, Merante-Boschin I, Pelizzo MR, Mauricio D, Opocher G, Rodríguez-Antona C, González-Neira A, et al: The variant rs1867277 in FOXE1 gene confers thyroid cancer susceptibility through the recruitment of USF1/USF2 transcription factors. PLOS Genet 2009, 5:e1000637.

44. Takahashi M, Saenko VA, Rogounovitch TI, Kawaguchi T, Drozd VM, Takigawa-Imamura H, Akulevich NM, Ratanajaraya C, Mitsutake N, Takamura N, Danilova LI, Lushchik ML, Demidchik YE, Heath S, Yamada R, Lathrop M, Matsuda F, Yamashita S: The FOXE1 locus is a major genetic determinant for radiation-related thyroid carcinoma in Chernobyl. Hum Mol Genet 2010, 19:2516-2523. 
45. Biondi B, Filetti S, Schlumberger M: Thyroid hormone therapy and thyroid cancer: a reassessment. Nat Clin Pract Endocrinol Metab 2005, 1:32-40.

46. Kim EY, Kim WG, Kim WB, et al: Coexistence of chronic lymphocytic thyroiditis is associated with lower recurrence rates in patients with papillary thyroid carcinoma. Clin Endocrinol (Oxf) 2009, 71:581-586.

47. Kim SS, Lee BJ, Lee JC, Song SH, Kim BH, Son SM, Kim IJ, Kim YK, Kang YH: Preoperative serum thyroid stimulating hormone levels in welldifferentiated thyroid carcinoma is a predictive factor for lateral lymph node metastasis as well as extrathyroidal extension in Korean patients: a single-center experience. Endocrine 2011, 39:259-265.

48. Hanahan D, Weinberg RA: Hallmarks of cancer: the next generation. Cell 2011, 144:646-674.

49. Grivennikov SI, Greten FR, Karin M: Immunity, inflammation, and cancer. Cell 2010, 140:883-899.

50. Qian BZ, Pollard JW: Macrophage diversity enhances tumor progression and metastasis. Cell 2010, 141:39-51.

51. Arora N, Scognamiglio T, Zhu B, Fahey TJ 3rd: Do benign thyroid nodules have malignant potential? An evidence-based review. World J Surg 2008, 32:1237-1246.

52. Zhang L, Wei WJ, Ji QH, Zhu YX, Wang ZY, Wang Y, Huang CP, Shen $Q$, Li DS, Wu Y: Risk factors for neck nodal metastasis in papillary thyroid microcarcinoma: a study of 1066 patients. J Clin Endocrinol Metab 2012, 97:1250-1257.

doi:10.1186/1471-2407-12-610

Cite this article as: Zhang et al:: The clinical features of papillary thyroid cancer in Hashimoto's thyroiditis patients from an area with a high prevalence of Hashimoto's disease. BMC Cancer 2012 12:610.

\section{Submit your next manuscript to BioMed Central and take full advantage of:}

- Convenient online submission

- Thorough peer review

- No space constraints or color figure charges

- Immediate publication on acceptance

- Inclusion in PubMed, CAS, Scopus and Google Scholar

- Research which is freely available for redistribution 